\title{
CHROMOSOME ABNORMALITIES IN RABBIT BLASTOCYSTS FOLLOWING DELAYED FERTILIZATION
}

\author{
EVELYN L. SHAVER AND D. H. CARR \\ Department of Anatomy, University of Western Ontario, \\ London, Ontario, Canada
}

(Received 23rd September 1966)

\begin{abstract}
Summary. Rabbits were mated at timed intervals after an ovulationinducing injection of chorionic gonadotrophin. Blastocysts were recovered at autopsy 6 days after mating and examined cytogenetically for chromosome abnormalities. A marked decrease in the number of blastocysts recovered occurred at delayed ovulation-mating time intervals greater than $10 \mathrm{hr}$. Thirteen chromosome aberrations arose among 135 blastocysts examined. Triploidy was the commonest anomaly and was found in six instances from rabbits mated 8 and $9 \mathrm{hr}$ after injection of gonadotrophin. Fewer abnormalities occurred at the remaining delayed intervals. In addition, a pentaploid, two mixoploids and a trisomy were obtained from animals mated immediately following injection.
\end{abstract}

\section{INTRODUCTION}

The effects of delayed fertilization have been studied in various species. Hammond (1934) reported a progressive decrease in litter size in rabbits when mating occurred between $5 \mathrm{hr}$ before and $2 \mathrm{hr}$ after ovulation. He attributed the loss of fertility to aged ova not being fertilized. In addition to decreased litter size, anomalies in early stages of development and increased embryonic mortality were observed following delayed insemination in guinea-pigs (Blandau \& Young, 1939), rats (Blandau \& Jordan, 1941) and rabbits (Chang, 1952). Thus, when aged ova were fertilized, an increase in abnormalities and foetal loss was found. Witschi (1952) reviewed the subject of over-ripeness of ova as a cause of abnormalities and reported on experiments in amphibia. The effect of delayed mating on the proportion of eggs fertilized in the rabbit was studied by Adams \& Chang (1962a). A marked decline in number of fertilized ova was noted when mating was delayed $12 \mathrm{hr}$ after an ovulation-inducing injection of luteinizing hormone. At 14 hr delay, no ova were fertilized.

The recent work of Carr (1963, 1965), in which chromosome anomalies occurred in $22 \%$ of early spontaneous abortions, demonstrated the importance of chromosome abnormalities in embryonic and foetal loss in the human. Witschi \& Laguens (1963) reported chromosome aberrations in embryos from over-ripe frog eggs and concluded that aged ova are an important cause of chromosomal non-disjunction during meiosis and mitosis. 
This report concerns chromosome studies of rabbit blastocysts following delayed fertilization.

\section{MATERIAL AND METHODS}

Thirty-seven female rabbits of New Zealand White and Flemish Giant breeds were used in this study. All does were caged separately for at least 3 weeks before mating. The mean weight of the rabbits was $3.74 \pm 0.09 \mathrm{~kg}$ (range 2.7 to $4 \cdot 6 \mathrm{~kg}$ ). Ovulation was induced by an intravenous injection of 25 i.u. chorionic gonadotrophin ('A.P.L.' Ayerst Laboratories). This results in ovulation occurring approximately $10 \mathrm{hr}$ later (Harper, 1963). Does were mated at intervals varying from 0 to $14 \mathrm{hr}$ after injection (Table 1). Seven females were mated immediately after injection and three at each of the delayed time intervals. After mating, each doe was checked for the presence of spermatozoa. The animals were killed 6 days later, the uterine horns flushed with warm saline and the blastocysts recovered. The number of corpora lutea in the ovaries was recorded as an indication of the number of ova shed.

Immediately after removal from the uterus, the blastocysts were placed in tissue culture medium 199 to which Colcemid had been added. After $1 \frac{1}{2} \mathrm{hr}$ incubation at $37^{\circ} \mathrm{C}$, each blastocyst was placed in $0.9 \%$ sodium citrate in a siliconized centrifuge tube and dissociated by aspiration with a siliconized Pasteur pipette. After 10-min incubation, the cells were centrifuged at $800 \mathrm{rev} / \mathrm{min}$ for 5 min, the supernatant removed and replaced by alcohol-acetic acid $(3: 1)$ fixative. The preparations were stored overnight at $4^{\circ} \mathrm{C}$. After centrifugation and removal of the fixative, $45 \%$ acetic acid (aqueous) was added. Following a second change of acetic acid, the cells were resuspended and dropped onto a slide warmed to $56^{\circ} \mathrm{C}$ on a hot plate. The preceding method is a modification of the technique described by Ford \& Woollam (1963). The slides were stained with carbol fuchsin as outlined by Carr \& Walker (1961). Preparations were examined under an oil immersion objective. Karyotypes were made from metaphase plates suitable for photography and the chromosomes classified according to the idiogram for the rabbit, published by Nichols, Levan, HansenMelander \& Melander (1965).

\section{RESULTS}

The results are summarized in Tables 1 and 2. Twenty-three female rabbits mated successfully. A mean number of $10 \cdot 6 \pm 0.4$ (range 7 to 16) corpora lutea/ rabbit was recorded and a total of 154 blastocysts was recovered at autopsy 6 days after injection and mating. Thirteen chromosome anomalies arose among 135 blastocysts suitable for counting and for which karyotypes could be established.

The number of blastocysts obtained was influenced by the delay between gonadotrophin injection and mating (Table 1). When the interval was between 0 and $6 \mathrm{hr}$, a recovery rate of $87 \%$ was obtained. However, a pronounced decrease in the ratio of blastocysts recovered to number of corpora lutea counted became evident after delays of $10 \mathrm{hr}$ or more. One exception occurred at the $13 \mathrm{hr}$ delay period. Nine blastocysts were washed from the uterus of a 
PLATE 1

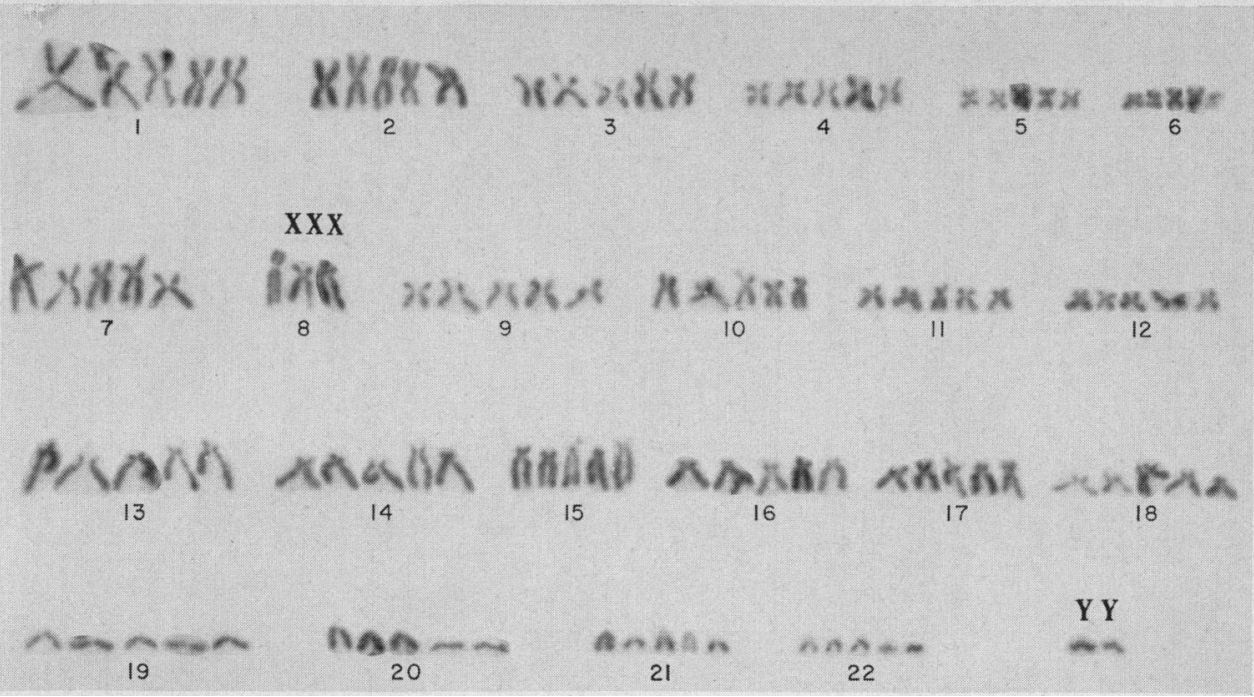

Fig. 1. Pentaploid karyotype with XXXYY sex chromosome complex.

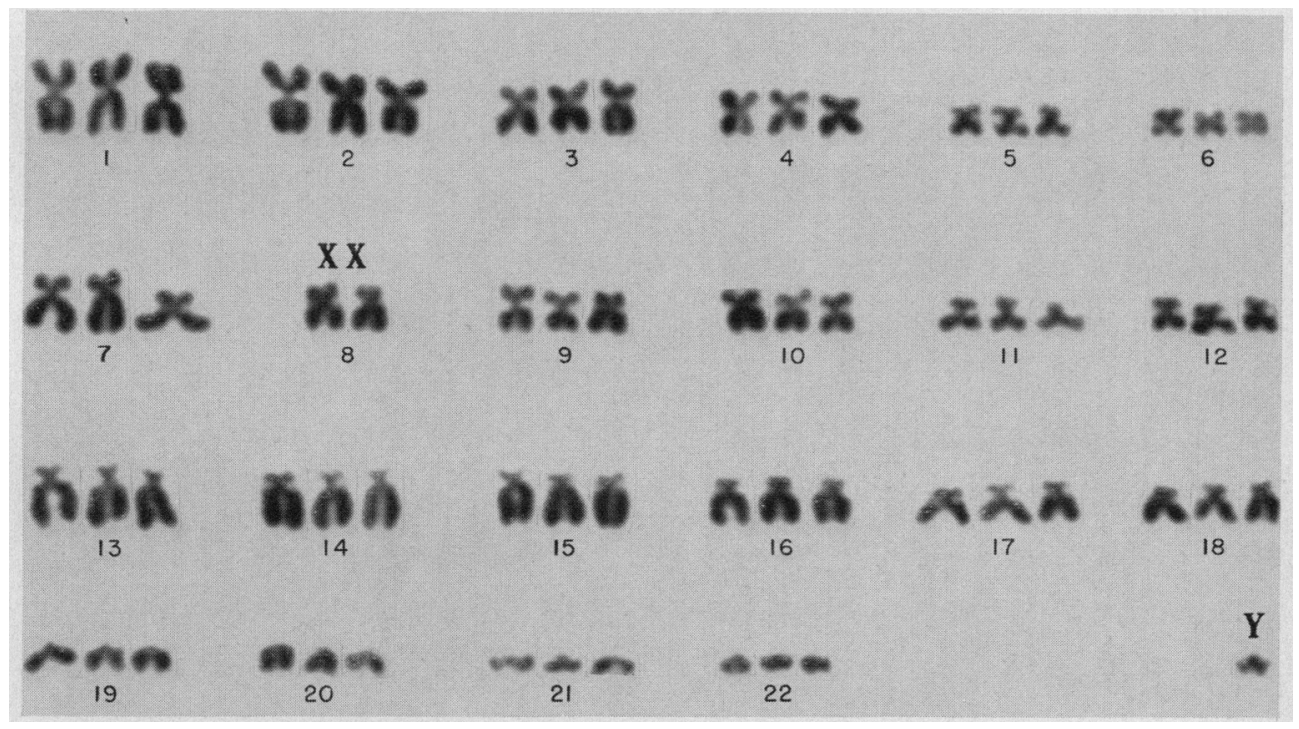

FIG. 2. Triploid karyotype with XXY sex chromosome complex.

(Facing p. 416) 
doe in which nine corpora lutea were counted in the ovaries. No blastocysts were obtained from the uterine horns of the other two rabbits mated $13 \mathrm{hr}$ after injection.

The normal diploid number for the rabbit is 44 (Melander, 1956). Cytogenetic features of the chromosomally abnormal blastocysts are listed in Table 2.

Animals mated immediately following gonadotrophin injection yielded five of forty-two or $12 \%$ chromosome anomalies. Polyploidy was the commonest feature with two mixoploids and a pentaploid recovered. Each mixoploid had a proportion of the cells in the octaploid range. Plate 1, Fig. 1 depicts the karyotype of the pentaploid blastocyst. The sex chromosome complex was XXXYY. The only trisomy found in the series occurred in this group. Chromosome number 1 was present three times to give a total count of forty-five chromosomes in the cells of the blastocyst. Another blastocyst, although having a normal diploid count of forty-four, when karyotyped was discovered to possess six small acrocentrics. A fragment of an arm seemed to be lacking from one chromosome of either pair 3 or 7 . Also, one chromosome was missing from pair 17.

TABLE 1

RELATIONSHIP BETWEEN NUMBER OF 6-DAY BLASTOCYSTS RECOVERED AND THE DELAY (HR) FROM INJEGTION OF CHORIONIC GONADOTROPHIN TO MATING

\begin{tabular}{|c|c|c|c|c|c|c|c|c|c|c|c|c|}
\hline & \multicolumn{11}{|c|}{ Delay (hr) } & \multirow{2}{*}{ Total } \\
\hline & 0 & 2 & 4 & 6 & 8 & 9 & 10 & 11 & 12 & 13 & 14 & \\
\hline $\begin{array}{l}\text { No. of successful matings } \\
\text { No. of corpora lutea } \\
\text { No. of blastocysts recovered }\end{array}$ & $\begin{array}{c}5 \\
38 * 2 \\
43\end{array}$ & $\begin{array}{r}2 \\
21 \\
20\end{array}$ & $\begin{array}{r}1 \\
11 \\
9\end{array}$ & $\begin{array}{r}1 \\
12 \\
11\end{array}$ & $\begin{array}{r}3 \\
43 \\
32\end{array}$ & $\begin{array}{r}3 \\
28 \\
19\end{array}$ & $\begin{array}{l}1 \\
9 \\
2\end{array}$ & $\begin{array}{r}2 \\
23 \\
4\end{array}$ & $\begin{array}{r}1 \\
11 \\
4\end{array}$ & $\begin{array}{r}3 \\
27 \\
9\end{array}$ & $\begin{array}{r}1 \\
10 \\
1\end{array}$ & $\begin{array}{r}23 \\
233 \\
154\end{array}$ \\
\hline
\end{tabular}

* Number for four animals only. Twelve blastocysts were recovered from the fifth animal.

With the 2-, 4- and 6-hr delay periods, only one chromosome abnormality, a mixoploid, was found among thirty-four blastocysts studied. However, four atypical, very small ones could not be examined cytogenetically. These all occurred in a rabbit mated $4 \mathrm{hr}$ after injection. In the mixoploid approximately one-third of the cells counted had four chromosome sets, a greater tetraploid fraction than was encountered in normal blastocysts.

Blastocyst size, as judged by visual inspection, varied greatly. Ten very small blastocysts, barely visible to the naked eye, were recovered. Three were mixoploid, one had 44/47 chromosomes and the remainder could not be examined cytogenetically. Two of the triploids were smaller than average, the remaining four were within normal size range. The largest blastocyst recovered was the pentaploid.

Triploidy arose in blastocysts from rabbits mated 8 and $9 \mathrm{hr}$ after gonadotrophin injection. Plate 1, Fig. 2 is a karyotype of a triploid with an XXY sex chromosome complex. Five of the six triploids found among the forty-three blastocysts examined were recovered from two animals. Three sets of chromosomes were found in three out of nine and two out of five blastocysts from rabbits 6 and 7 as listed in Table 2. The sex chromosome complex was XXX 


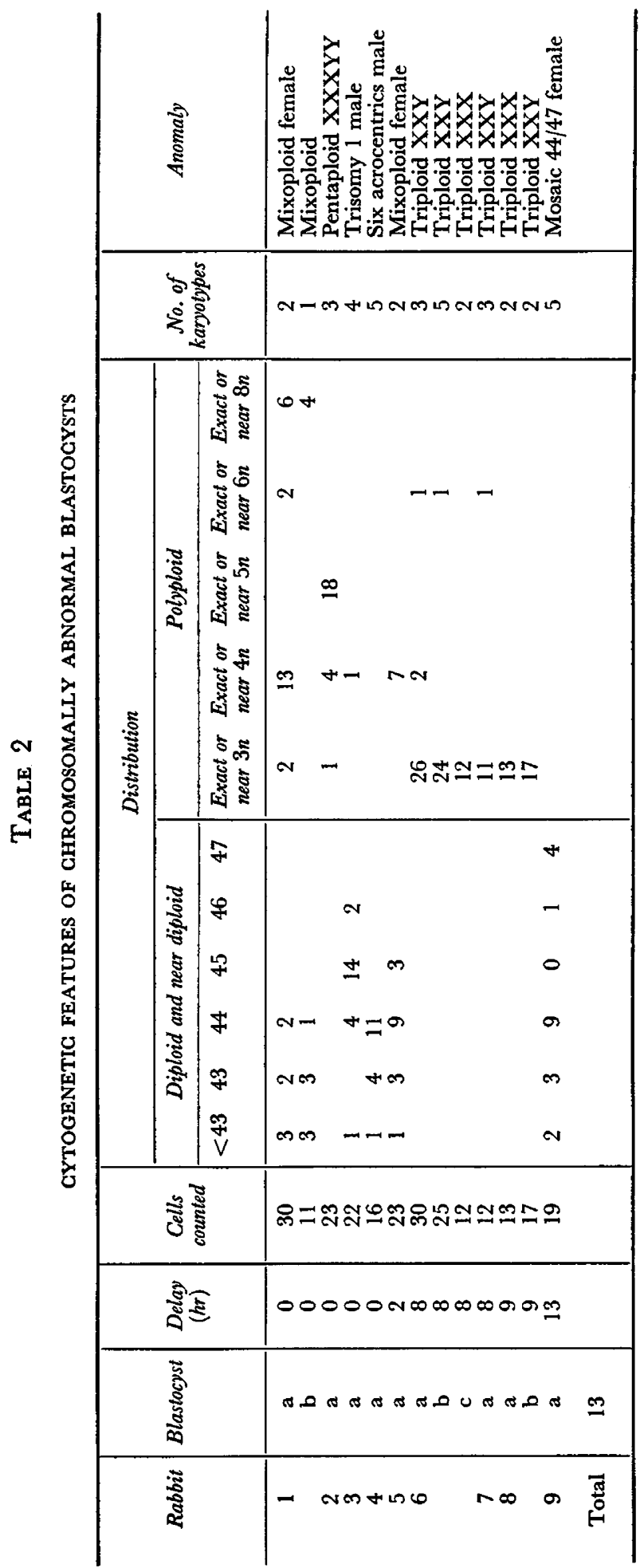


in two and XXY in four of the triploids. No abnormality other than triploidy was found at these delayed times, although two very small blastocysts were not studied chromosomally.

The number of blastocysts recovered from rabbits delayed 10 to $14 \mathrm{hr}$ between injection and mating was small in comparison to the number of corpora lutea present in the ovaries. Of the twenty blastocysts recovered, five were smaller in size than normal and seven had a greyish opaque cast to them. However, only one of the sixteen which could be examined cytogenetically was chromosomally abnormal. This was recovered from an animal mated $13 \mathrm{hr}$ after receiving chorionic gonadotrophin. Chromosome numbers of forty-four and a smaller cell population with forty-seven were present. Three karyotypes with forty-seven chromosomes showed the three extra chromosomes to be similar to numbers 4,6 and 19 . The sex chromosome complex was female.

\section{DISCUSSION}

This study of delayed mating following injection of chorionic gonadotrophin in rabbits resulted in a marked decrease of 6-day blastocysts recovered with delay intervals from 10 to $14 \mathrm{hr}$. Adams \& Chang (1962a) observed a decline in number of ova fertilized after delayed mating. The greatest number of unfertilized ova arose when rabbits were mated later than $12 \mathrm{hr}$ after injection of $\mathbf{L H}$. They attributed this to ova losing the capability to be fertilized before the spermatozoa became fully capacitated. Rabbit spermatozoa require at least $6 \mathrm{hr}$ in the female genital tract for maturation (capacitation) to occur (Chang, 1951; Adams \& Chang, 1962b; Dziuk, 1965). However, Adams \& Chang (1962a) did obtain 50 to $60 \%$ fertilized ova during 10 to 12 -hr delays. This was a greater fraction than the 25 to $30 \%$ recovery of 6 -day blastocysts in our study. The contradictory finding of nine blastocysts in a 13-hr delayed animal may be caused by individual variation in the time of follicular rupture and ovulation. Harper (1963) noted that ovulation may occur between $9 \frac{1}{2}$ to $13 \mathrm{hr}$ after either an injection of $\mathrm{LH}$ or mating.

Delayed fertilization leading to ovum ageing is one means of inducing suppression of the second polar body, polyspermy and fragmentation of the nucleus and blastomeres (Beatty, 1957). These result in polyploidy. The largest number of polyploids in our experiments arose in animals mated 8 and $9 \mathrm{hr}$ after an ovulation-producing injection. If capacitation of spermatozoa requires at least $6 \mathrm{hr}$, then fertilization occurred approximately 4 and $5 \mathrm{hr}$ after ovulation in these cases of triploidy. Bomsel-Helmreich (1965) induced suppression of the second polar body with Colcemid during in-vitro fertilization. A high incidence of triploid rabbit embryos resulted. Although triploidy has been reported in several mammalian species, no homogeneous triploid has been recorded after birth. Bomsel-Helmreich (1965) estimated death to occur before mid-gestation. This agrees with Carr's (1965) observation in early human abortions, where nine were triploids.

The abnormalities found in blastocysts from rabbits mated immediately after injection were more varied in chromosome constitution than those from delayed fertilizations. During preliminary experiments which are not reported here a 
vasectomized buck was used to induce ovulation. However, this method proved unsatisfactory and chorionic gonadotrophin injection was substituted. The administration of hormone, followed immediately by mating may have resulted in a new experimental factor being introduced. At present, a study is in progress to investigate this effect.

\section{ACKNOWLEDGMENTS}

This study was supported by grants from the Medical Research Council of Canada and the Joseph P. Kennedy Jr Medical Research Fund.

\section{REFERENCES}

Adams, C. E. \& Chang, M. C. (1962a) The effect of delayed mating on fertilization in the rabbit. 7. exp. Zool. 151, 155 .

Adams, C. E. \& Chang, M. C. (1962b) Capacitation of rabbit spermatozoa in the fallopian tube and in the uterus. F. exp. Zool. 151, 159.

Beatty, R. A. (1957) Parthenogenesis and polyploidy in mammalian development. Cambridge University Press, London.

BLANdau, R. J. \& Jordan, E. S. (1941) The effect of delayed fertilization on the development of the rat ovum. Am. F. Anat. 68, 275.

Blandau, R. J. \& Young, W. G. (1939) The effects of delayed fertilization on the development of the guinea pig ovum. Am. F. Anat. 64, 303.

Bomsel-Hezmreich, O. (1965) Heteroploidy and embryonic death. In Preimplantation Stages of Pregnancy, p. 246. Ciba Foundation Symposium, London.

CARR, D. H. (1963) Chromosome studies in abortuses and stillborn infants. Lancet, ii, 603.

CARR, D. H. (1965) Chromosome studies in spontaneous abortions. Obstet. Gynec., N.Y. 26, 308.

CARr, D. H. \& Walker, J. E. (1961) Carbol fuchsin as a stain for human chromosomes. Stain Technol. 36, 233.

Chang, M. C. (1951) Fertilizing capacity of spermatozoa deposited into the fallopian tubes. Nature, Lond. 168, 697.

Chang, M. C. (1952) Effects of delayed fertilization on segmenting ova, blastocysts and fetuses in rabbits. Fedn Proc. Fedn Am. Socs exp. Biol. 11, 24.

Dziuk, P. J. (1965) Double mating of rabbits to determine capacitation time. F. Reprod. Fert. 10, 389.

Ford, E. H. R. \& Wool.tam, D. H. M. (1963) A colchicine, hypotonic citrate, air drying sequence for foetal mammalian chromosomes. Stain Technol. 38, 271.

Hammond, J. (1934) The fertilization of rabbit ova in relation to time. J. exp. Biol. 11, 140.

HARPER, M. J. K. (1963) Ovulation in the rabbit: the time of follicular rupture and expulsion of the eggs, in relation to injection of luteinizing hormone. F. Endocr. 26, 307.

Melander, Y. (1956) The chromosome complement of the rabbit. Hereditas, 42, 432.

Nichols, W. W., Levan, A., Hansen-Melander, E. \& Melander, Y. (1965) The idiogram of the rabbit. Hereditas, 53, 63.

Wrтschi, E. (1952) Overripeness of the egg as a cause of twinning and teratogenesis: a review. Cancer Res. 12, 763.

Wrtschi, E. \& Laguens, R. (1963) Chromosomal aberrations in embryos from overripe eggs. Devl Biol. 7, 605 . 